\title{
O desenvolvimento das neoformações psíquicas na atividade de estudo
}

\author{
The development of psychic neoformations in learning activity
}

Cleber Barbosa da Silva Clarindo ${ }^{1}$

\begin{abstract}
RESUMO
Este artigo tem por objetivo fazer uma discussão sobre a relação entre a atividade de estudo e o desenvolvimento das neoformações psíquicas das crianças em idade escolar. Para a análise dessa relação, utilizamos o referencial teórico da Teoria Histórico-Cultural. Partindo dos conceitos de aprendizagem, desenvolvimento, zona de desenvolvimento próximo e atividade, buscamos explicitar como a organização da atividade de estudo constitui-se como um meio fundamental para que os estudantes dos anos iniciais do Ensino Fundamental se apropriem das principais neoformações psíquicas dessa etapa da vida, que são as capacidades próprias do pensamento teórico: análise, reflexão e planificação mental. O seu desenvolvimento tem relação direta com a organização da atividade de ensino que orienta a aprendizagem dos escolares no início do processo de escolarização.
\end{abstract}

Palavras-chave: Educação. Atividade de Estudo. Capacidades do Pensamento Teórico.

\begin{abstract}
This article aims to discuss the relationship between learning activity and the development of psychic neoformations in schoolchildren. For the analysis of this relationship, we used the theoretical framework of Cultural-Historical Theory. Starting from the concepts of learning, development, zone of proximal development and activity, we tried to make explicit how the organization of learning activity is a fundamental means for the students of the Early Years of Elementary Education to appropriate the main psychic neoformations of this period of life, that are the capacities of theoretical thinking: analysis, reflection and mental planning. Their development is directly related to the organization of teaching activity that orients schoolchildren learning that is offered to children at the beginning of schooling process.
\end{abstract}

Keywords: Education. Learning Activity. Theoretical Thinking Capabilities.

\section{Introdução}

Como já classicamente difundida pelos teóricos da Teoria Histórico-Cultural, a atividade de estudo é a forma principal de atividade das crianças em idade escolar, tendo papel essencial no processo de desenvolvimento da personalidade das crianças entre 6 e 10 anos. Dada essa importância, a compreensão das neoformações psíquicas deve ser objeto de qualquer processo educativo que vise ao desenvolvimento das

\footnotetext{
${ }^{1}$ Doutor em Educação pela Faculdade de Filosofia e Ciências - Universidade Estadual Paulista UNESP - Campus de Marília - Professor da Rede Pública Estadual de São Paulo - Brasil. ORCID. https://orcid.org/0000-0002-2668-2068. E-mail: cleber.clarindo@unesp.br.
} 
máximas possibilidades humanas, pois são elas que permitem aos seres humanos a compreensão da realidade em sua totalidade.

Pensar o processo educativo implica planejar, sistematizar e organizar a ação pedagógica que, por meio dos conhecimentos científicos, produzidos historicamente pela humanidade, levará à constituição de novas capacidades psíquicas no sujeito à medida que este se insere ativamente no processo de aprendizagem. Essas capacidades resultam do desenvolvimento e da efetivação de um conjunto de neoformações psíquicas humanas, efetivadas pela apropriação dos conhecimentos científicos e, ao mesmo tempo, dialeticamente, uma forma para apropriação desses conhecimentos.

Nesse contexto, compreender a relação entre aprendizagem e desenvolvimento é essencial para a análise da relação entre atividade de estudo e o desenvolvimento das neoformações das crianças em idade escolar.

\section{A relação entre aprendizagem e desenvolvimento na Teoria Histórico-Cultural.}

A partir das contribuições de Vigotski (1896-1934), o desenvolvimento humano passa a ser compreendido em outro patamar; antes dos trabalhos do psicólogo soviético, a compreensão sobre a relação aprendizagem-desenvolvimento era pautada pelo entendimento de que esses processos se davam em uma curva sempre ascendente, ou seja, em um processo baseado em uma evolução biológica.

Em contraposição a essa concepção, Vygotski (2012, p. 29) distingue, na ontogênese humana, duas raízes para o processo de desenvolvimento das formas superiores de conduta, que, embora sejam de naturezas diferentes, unem-se, indissoluvelmente, nesse percurso: de um lado, os "processos de domínio dos meios externos do desenvolvimento cultural e do pensamento: a linguagem, a escrita, o cálculo, o desenho", e, de outro, "os processos de desenvolvimento das funções psíquicas superiores especiais" como a atenção voluntária, a memória lógica, a formação de conceitos, etc., caracterizando a condicionalidade histórico-cultural do desenvolvimento psíquico, em oposição a uma concepção tradicional que não conseguia diferenciar os aspectos biológicos 
e culturais do desenvolvimento, confundindo ambos e ocasionando, em consequência, uma visão simplista para um fenômeno tão complexo.

Vygotski (2012) propõe uma compreensão dialética da relação aprendizagem-desenvolvimento, implicando que, para compreender a totalidade do desenvolvimento humano, é necessário considerar a dinâmica de contradições, de confrontos entre o natural e o histórico, o biológico e o cultural e entre o orgânico e o social, que decorrem da inserção dos sujeitos na prática social.

A base desse processo são as formas primitivas de conduta humana vinculadas às funções psicológicas elementares, a partir das quais formam-se as condutas superiores, em um processo de lutas e de superação, por incorporação, dessas estruturas. $\mathrm{O}$ que antes era entendido como uma linha reta pela psicologia tradicional, agora é compreendido como um conjunto de rupturas entre as estruturas antigas e as novas formas de conduta, caracterizando um desenvolvimento que se faz por saltos revolucionários.

$\mathrm{O}$ efeito que a concepção vigotskiana de desenvolvimento psíquico tem na organização do ensino é uma transformação radical no processo educativo. Se, antes, a educação era meramente um processo de adaptação das crianças ao ritmo de seu desenvolvimento natural, que considerava seguir os caminhos, os limites das formas de percepção e de pensar dos sujeitos, agora, do novo ponto de vista, necessário se faz superar os limites biológicos e entender o desenvolvimento humano como movimento dinâmico de relações entre forças naturais e culturais, pelo qual transformam-se e estruturam-se as aptidões e capacidades históricas e sociais, caracterizando um processo complexo de mudanças radicais no curso do desenvolvimento humano.

Outro aspecto a ser considerado na compreensão do processo de superação das concepções que naturalizam a relação entre desenvolvimento e aprendizagem diz respeito ao conceito de zona de desenvolvimento próximo (também conhecida como proximal, potencial, iminente). A relação entre aprendizagem e desenvolvimento, segundo Vygotski (2001), considera, por um lado, um nível de desenvolvimento real, que pode ser definido como as formas já estabelecidas das 
funções e capacidades psicológicas e, por outro lado, uma zona de desenvolvimento que se refere às funções ainda em processo de formação.

O nível de desenvolvimento real compreende, então, formas de conduta e ação que os sujeitos têm formadas em um determinado período do seu desenvolvimento e revela a capacidade para solucionar problemas e realizar tarefas autonomamente. Demonstra o que a criança pode fazer em uma determinada circunstância da realidade, naquele momento específico, indicando que os processos intelectuais estão em consonância com os ciclos de desenvolvimento já conquistados. Por outro lado, a zona de desenvolvimento próximo compreende a potencialidade das capacidades humanas que estão em processo e orienta, quando uma criança não consegue realizar determinada atividade sozinha, a atuação docente ou de outra criança mais experiente, que mobilizará suas funções em processo de formação, e ela chegará, progressivamente, a uma nova aprendizagem e consequente desenvolvimento.

Nessa relação dinâmica entre processo de aprendizagem e desenvolvimento, considerando-se, principalmente, os processos que ainda estão por vir, em movimento, está a possibilidade de a criança, em meio a ações de cooperação, se apropriar de novos conhecimentos e desenvolver suas funções psicológicas superiores. Nas palavras de Vigotskii (1988, p. 113), "o que a criança pode fazer hoje com o auxílio dos adultos poderá fazê-lo amanhã por si só”. Isso implica a relevância de situações em que haja ação conjunta, diálogo, colaboração, troca de experiências e interação entre pessoas; fatores essenciais para que esse processo gere o desenvolvimento que "é a fonte de todas as propriedades especificamente humanas da consciência da criança" (VYGOTSKI, 2001, p. 241).

A relação entre aprendizagem e desenvolvimento, assim entendida, fundase sobre uma lei geral segundo a qual "toda função no desenvolvimento cultural da criança aparece em cena duas vezes, em dois planos; primeiro no plano social e depois no plano psicológico" (VYGOTSKI, 2012, p. 150). Compreendemos, a partir dessa lei, que por detrás de todas as formas superiores de conduta se encontram, como origem, as relações sociais, ou seja, que todas as funções psíquicas superiores constituem-se como resultados internalizados de origem social. 
A ação pedagógica que se orienta pelos fundamentos teóricos que consideram a compreensão dialética da relação entre aprendizagem e desenvolvimento e os conceitos de zona de desenvolvimento próximo e da lei geral do desenvolvimento consegue, no encaminhamento do trabalho educativo, determinar os futuros passos do processo de desenvolvimento infantil. Desta forma, busca examinar o que já foi apropriado pela criança e procura criar meios adequados de organização pedagógica, visando à formação de funções psíquicas superiores.

A atividade de estudo, em sua estruturação, considera esses fundamentos como essenciais para o desenvolvimento das neoformações psíquicas próprias das crianças escolares (DAVYDOV, 1999). Mas, como esse processo se estabelece? Qual a base para o desenvolvimento das neoformações psíquicas nos seres humanos? Discutiremos o assunto a seguir, enfatizando a teoria da atividade (LEONTIEV, 1978; 2004).

\section{A atividade como elemento prático de desenvolvimento das neoformações psíquicas humanas}

A teoria da atividade torna-se fundamental para a compreensão da relação entre a atividade de estudo e o desenvolvimento das neoformações psíquicas das crianças em idade escolar. Tal como concebida por Leontiev e seus colaboradores, essa teoria defende que o desenvolvimento dos seres humanos ao longo da história acontece graças aos avanços no processo produtivo da humanidade, reflexo da evolução das formas de produção que se efetivam pelo trabalho, atividade que medeia as relações do homem com a natureza. A universalização desse processo e o grande acúmulo de riquezas materiais e culturais daí decorrente são as fontes essenciais para o desenvolvimento do próprio homem como ser social.

A atividade é, pois, uma característica essencialmente humana de transformação da realidade que tem a capacidade de promover a formação dos meios mais desenvolvidos de reflexo da realidade, estabelecidos de maneira tão complexa que permitem aos seres humanos a produção de seus próprios meios de subsistência, que resultam das relações produtivas e sociais historicamente constituídas pela humanidade. Em meio a essas relações, encarnadas nas mais 
diversas atividades humanas, que expressam as condições materiais de vida dos sujeitos, tem origem o psiquismo humano (LEONTIEV, 2004).

Em outros termos, por meio da atividade, condicionada pelos modos de vida, trabalho e relações sociais permeadas pela linguagem, desenvolvem-se todas as funções psíquicas superiores. O psiquismo é, então, compreendido como uma forma peculiar decorrente da atividade; é produto que deriva das relações materiais do homem em sociedade. Entendemos que a atividade material externa, no processo de inserção do homem em sua realidade histórico-cultural, transforma-se em atividade interna, em atividade de sua própria consciência (LEONTIEV, 1978).

Essa compreensão implica a necessidade de analisar como está estruturada a atividade, reconhecida como meio de compreender o desenvolvimento psíquico humano, porque está nela o movimento vivo do processo de relação entre o homem e sua realidade, estando aí presentes todos os elementos que constroem e objetivam essa relação. A compreensão acerca da estrutura da atividade possibilita ir aos fundamentos das relações entre a atividade dos homens e o desenvolvimento das suas neoformações psíquicas.

Da compreensão da forma pela qual está estruturada a atividade e sua influência no desenvolvimento das neoformações psíquicas humanas resulta sua relevância teórica, metodológica e conceitual: primeiro porque na estrutura da atividade está a base para a análise da atividade de estudo como atividade principal das crianças em idade escolar e, segundo, porque está também na atividade o fundamento para a compreensão do processo de desenvolvimento das neoformações psíquicas dessas crianças, as suas capacidades de análise, reflexão e planificação mental que, ao serem desenvolvidas durante a atividade de estudo, conduzem à formação do pensamento teórico, o pensamento estruturado por meio de conceitos.

Para a compreensão da atividade humana não podemos partir de um conceito geral, abstrato, porque

[...] a rigor, nós nos ocupamos sempre de atividades particulares, cada uma das quais responde a determinada necessidade do sujeito, tende ao objeto dessa necessidade, desaparece quando essa necessidade é satisfeita e torna a reproduzir-se, talvez já em 
condições totalmente distintas e modificadas. (LEONTIEV, 1978, p. 81, tradução nossa, grifo no original).

A característica que essencialmente diferencia uma atividade de outra é, então, o seu caráter objetivo; encontra-se no objeto da atividade a orientação para o sujeito da atividade. Nas palavras de Leontiev, "o que distingue uma atividade de outra, é a diferença de seus objetos, já que é o objeto da atividade que lhe confere determinada orientação" (LEONTIEV, 1978, p. 82, tradução nossa).

Essa natureza objetal da atividade engendra tanto a necessidade de sua realização como orienta o sujeito no processo de satisfazê-la. Na relação entre a necessidade sentida pelo sujeito e a busca de um objeto que a satisfaça, surge o motivo para agir na direção da conquista desse objeto. Assim, o motivo concreto da atividade está no próprio objeto, que busca sempre a satisfação de uma necessidade: todo motivo da atividade é sempre uma necessidade objetivada que conduz o sujeito à ação (LEONTIEV, 1978).

Desse ponto de vista, "não há atividade sem motivo: atividade não motivada não é uma atividade carente de motivo, e sim, uma atividade com um motivo subjetiva e objetivamente oculto" (LEONTIEV, 1978, p. 82, tradução nossa), uma vez que toda atividade organiza-se em torno de um objeto, sendo que o motivo para agir está no próprio objeto.

O motivo tem, então, papel articulador entre a necessidade e o objeto. Essa articulação fica clara quando compreendemos as funções exercidas pelo motivo no processo de estruturação de uma atividade. Nesse processo, ele cumpre uma dupla função: a primeira, é sua função estimuladora, destinada a impulsionar a atividade; é pelo motivo da atividade que as necessidades são transformadas em necessidades objetivadas, conduzindo o sujeito à realização daquelas ações que geram o resultado esperado por ele. A segunda função do motivo refere-se ao processo de criação de sentidos para a atividade: o resultado das ações realizadas pelo sujeito da atividade produz nele um sentido vital.

Toda ação, na estrutura da atividade, tem dois aspectos; o primeiro é sua intencionalidade, sempre buscando pelo objeto da atividade e movendo-se em direção ao objetivo a ser conquistado. O segundo, é seu elemento operacional, isto 
é, as operações, que são os meios de execução da ação orientada a um fim, e são determinados pelas condições objetivas e materiais requeridas para o cumprimento da ação. Nessa dinâmica entre ações e operações organiza-se e desenvolve-se uma tarefa, que "é precisamente um fim que se dá em determinadas condições" (LEONTIEV, 1978, p. 85, tradução nossa).

Ações e operações, embora possam ser diferenciadas entre si, são processos que integram um todo dialético e sistemático denominado atividade. Leontiev (1978) considera essencial compreender a dinâmica da estrutura interna da atividade para a compreensão dos fenômenos do desenvolvimento humano, ao afirmar que, sem o entendimento dos vínculos sistêmicos internos da atividade, não é possível resolver os processos mais simples de análise do desenvolvimento humano. Segundo o autor,

Para investigar a atividade o que se requer é analisar seus vínculos sistêmicos internos. De outro modo não estamos em condições de resolver nem sequer as tarefas mais simples, como por exemplo, julgar se em um dado caso estamos ante uma ação ou operação. Além disso, a atividade é um processo caracterizado por transformações que se produzem constantemente. A atividade pode perder o motivo que a originou e então se converter em uma ação que talvez efetive uma relação totalmente diferente com o mundo, outra atividade; a ação, pelo contrário, pode adquirir uma força impulsionadora própria e chegar a ser uma atividade particular; por último, a ação pode transformar-se em um meio para alcançar um fim, em uma operação capaz de efetuar diversas ações. (LEONTIEV, 1978, p. 87, tradução nossa, grifo no original).

Um outro elemento importante para compreender a constituição das neoformações psíquicas ao longo do desenvolvimento humano é o caráter dinâmico da estrutura da atividade humana, que remete à compreensão dos nexos envolvidos nos processos da ontogênese, pois no dinamismo da estrutura da atividade está a chave para elucidar as possibilidades históricas do desenvolvimento das capacidades humanas. É por isso que a proposta da Educação Desenvolvimental e a da atividade de estudo têm na atividade humana um pilar metodológico, conceitual e ideológico como a essência de uma educação transformadora.

Dessa maneira, para compreender as origens da atividade de estudo e as necessidades que permitem o seu advento, bem como o consequente 
desenvolvimento das neoformações materializadas no desenvolvimento das capacidades do pensamento teórico, faz-se essencial compreender a história do desenvolvimento do conjunto das atividades humanas, ou seja, necessário se faz realizar a análise da periodização das atividades dos seres humanos e de como, em cada etapa da vida humana, as suas atividades possibilitam a constituição e o desenvolvimento de neoformações psíquicas.

\section{As neoformações psíquicas como resultado histórico das atividades humanas e a atividade de estudo}

Quando buscamos a essência de uma etapa do desenvolvimento infantil ou dos processos a ela relacionados, como a educação, devemos partir das conexões entre as forças que regem e movem o conjunto do psiquismo humano. Dessa maneira, a análise do desenvolvimento das neoformações psíquicas e sua relação com a atividade de estudo, no caso deste artigo, implica compreender como os indivíduos, por sua atividade, se relacionam, em cada período da sua vida, com a realidade. Somente pela análise da forma como ocorre a apropriação, pela atividade, das relações sociais, históricas e culturais que acontecem ao longo da vida e se complexificam nesse processo, podemos entender as determinações do desenvolvimento das neoformações psíquicas das crianças.

A atividade que dirige os saltos qualitativos que acontecem em função dos avanços no desenvolvimento psíquico em certo período da vida denomina-se atividade principal. Ela é definida por três características: 1) tem origem em outras formas de atividade e dá origem a outras formas de atividade em um processo de diferenciação constante; 2) é base para formação e desenvolvimento de processos psíquicos particulares que têm relação com atividade principal; 3) é motor do desenvolvimento das principais mudanças psicológicas da personalidade da criança em determinada etapa do desenvolvimento (LEONTIEV, 1988). "A atividade principal é então a atividade cujo desenvolvimento governa as mudanças mais importantes nos processos psíquicos e nos traços psicológicos da personalidade da criança, em um certo estágio de seu desenvolvimento” (LEONTIEV, 1988, p. 65). 
Cada uma das atividades principais tem potencial de desenvolvimento de neoformações psíquicas que são características vinculadas às formas de relação com a realidade. Excetuando-se o período da lactância, que se caracteriza como a pré-história do desenvolvimento da criança (RUBINSTEIN, 1974), dadas as poucas formas de relação do bebê com a realidade, nos demais períodos de vida da criança, ela, ativamente, se relaciona com as pessoas e com os objetos que estão a sua volta, desenvolvendo suas capacidades psíquicas.

A atividade de estudo é a atividade principal da criança em idade escolar inicial, ou seja, no conjunto das atividades humanas, a atividade de estudo é a que representa a principal forma de relação das crianças com o mundo que as rodeia e, principalmente, com a escola. É por meio dessa atividade que as crianças, nessa etapa do seu desenvolvimento, apropriam-se dos rudimentos das mais elaboradas formas de conhecimento da realidade criadas pelo gênero humano, representadas nos produtos culturais como as ciências e as artes, além de outras formas de conhecimentos elaborados que lhes permitem sair dos limites da vida cotidiana.

A atividade de estudo, como todas as atividades humanas, se configura como a unidade entre o conjunto dos bens sociais e a atividade viva dos sujeitos que produzem esses bens. $\mathrm{Na}$ atividade de estudo, essa unidade se configura como resultado da apropriação, pelo sujeito, de novas formas internas de atividade, caraterizadas pelas ações mentais realizadas sobre os objetos da realidade, em um processo mediado pela linguagem e cuja trajetória vai do externo ao interno, consoante a lei geral de desenvolvimento (VYGOTSKI, 2012) mencionada anteriormente.

Assim, a aquisição das ações mentais, que estão na base da apropriação pelo indivíduo da "herança" dos conhecimentos e conceitos elaborados pelo homem, supõe necessariamente que o sujeito passe das ações realizadas no exterior às ações situadas no plano verbal, depois a uma internalização progressiva destas últimas; o resultado é que estas ações adquirem o caráter de ações intelectuais estreitas de atos intelectuais. (LEONTIEV, 2004, p. 200, grifo no original).

Como característica principal da atividade de estudo, as formas que se interiorizam não apenas se concretizam como meio diferenciado de relações 
sociais, mas, principalmente, como meio de desenvolvimento do próprio sujeito da atividade, uma vez que a atividade de estudo, em seus processos de efetivação, possibilita o processo de autotransformação do sujeito. Repkin (2014) ilustra essas diferenças de objetivos e resultados da atividade de estudo em relação a qualquer outro tipo de atividade ao afirmar que

Qualquer outro tipo de atividade é voltado para a obtenção de resultados externos. Na atividade de pesquisa, por exemplo, é importante obter novas descobertas (caso contrário, a atividade perde sentido). $\mathrm{O}$ mesmo vale para a atividade lúdica. A criança não brinca para se tornar mais inteligente. A tarefa consiste em um objetivo externo: reproduzir, com a maior precisão possível, o sistema das relações humanas. [...] $\mathrm{Na}$ atividade de estudo, o objetivo é bem diferente. Nesse caso, tanto o objetivo como o resultado não são um produto externo, mas uma mudança dentro de si mesmo como sujeito da atividade. Em outras palavras, a atividade de estudo deve ser entendida como atividade para a autotransformação do sujeito. (REPKIN, 2014, p. 88).

Essa característica da atividade de estudo permite que o sujeito tenha consciência de suas capacidades de transformação da realidade e, consequentemente, de governar seu próprio desenvolvimento, processo esse que é fruto da síntese histórica das atividades que fazem do homem, verdadeiramente, um sujeito e parte integrante do gênero humano.

Para chegar a esse desenvolvimento, a atividade de estudo elege como seu objeto de estudo o conhecimento teórico, definido como aquele "que representa as inter-relações entre o interno e o externo, entre o ser e a aparência, entre o original e o derivado" (DAVYDOV, 1999, p. 126). A apropriação do conhecimento teórico, encarnado nos conceitos científicos, e o desenvolvimento das habilidades a ele relacionadas, constituem o meio pelo qual a atividade de estudo é organizada e implementada. Como a apropriação desses conhecimentos pressupõe uma adequada atividade para efetivar-se e não existe atividade sem seu objeto, seu conteúdo, "a atividade de estudo e o objeto de estudo devem ser considerados e organizados como uma unidade" (LOMPSCHER, 1999, p. 141). Nessa unidade, os conhecimentos científicos se configuram com um duplo papel: como conteúdo da atividade de estudo e, ao mesmo tempo, como impulsionadores 
do processo de desenvolvimento do pensamento teórico nos escolares. No processo de realização da atividade de estudo,

[...] a criança, sob a direção do professor, vai assimilando sistematicamente o conteúdo das formas desenvolvidas da consciência social (a ciência, a arte, a moral, e o direito) e as capacidades de atuar em correspondência com as exigências de ditas formas. O conteúdo destas formas de consciência social (conceitos científicos, imagens artísticas, valores morais, normas jurídicas) tem caráter teórico. (DAVIDOV, 1988, p. 82, tradução nossa).

É esse caráter teórico do conteúdo da atividade de estudo que, aliado a uma forma adequada de sua organização e implementação, conduz a criança à formação de seu pensamento teórico, que é a neoformação específica dessa atividade realizada pelos escolares da escola básica. A realização da atividade de estudos pelas crianças leva ao desenvolvimento do seu psiquismo e à transformação da relação da criança com a realidade.

$\mathrm{Na}$ atividade de estudo, o processo de apropriação dos conhecimentos científicos ocorre por via da solução autônoma, por parte dos estudantes, da tarefa de estudo, compreendida por Davídov (1988) como o seu principal componente, que expressa a unidade entre o objetivo da ação e as condições para sua realização. As ações de estudo constituem, então, o meio pelo qual é resolvida a tarefa de estudo, que permite à criança a descoberta das condições de origem dos conhecimentos científicos, em um processo que estimula a busca pelo que não é conhecido e a consequente assimilação dos novos conhecimentos e métodos de ação, dando sentido à totalidade da atividade de estudo.

$\mathrm{Na}$ proposta de Davídov e seus seguidores (DAVÍDOV, 1988), a materialização da atividade de estudo acontece por meio de seis ações de estudo que compõem a tarefa de estudo. As quatro primeiras ações conduzem o estudante à formação do conceito presente no objeto de estudo, em um movimento que vai desde a descoberta de uma relação universal nos dados concretos sensíveis do objeto até a construção de um sistema de tarefas particulares a serem resolvidas pelo procedimento geral obtido ao final do processo. As duas últimas ações destinam-se ao controle da operacionalização das ações próprias da 
tarefa de estudo, e à avaliação dos resultados obtidos em sua resolução. A seguir, apresentamos as seis ações de estudo vistas em suas peculiaridades.

A primeira ação de estudo, considerada a principal delas, tem o papel de transformar os dados da tarefa com o objetivo de expor a relação universal do objeto estudado, buscando e descobrindo uma relação definida do objeto íntegro que deverá refletir-se no conceito teórico correspondente a essa relação. Atua como fonte da constituição do aspecto real dos dados transformados, como origem genética das peculiaridades do objeto integral, conformando o conteúdo da análise mental que configura o momento inicial do processo de formação do conceito.

A segunda ação de estudo consiste na modelação, sob a forma objetal, com letras ou gráfica, da relação universal encontrada inicialmente no material de estudo, objetivando fixar as características internas do objeto, não observáveis de maneira direta, e propiciar a atividade mental do sujeito sobre o objeto de estudo.

$\mathrm{Na}$ sequência, o estudante realiza a terceira ação de estudo, que consiste na transformação do modelo idealizado para conseguir estudar suas propriedades em forma pura e essencial, levando-o à descoberta das propriedades da relação universal do objeto de estudo.

A quarta ação refere-se ao processo de dedução e construção de um sistema de tarefas particulares que se resolvem por meio do procedimento geral encontrado no percurso das anteriores ações de estudo. Por meio dela, concretiza-se a tarefa de estudo a que se dedicou o estudante desde o princípio, permitindo-lhe a resolução das tarefas particulares, caracterizadas como variantes da tarefa inicial resolvida por ele.

A quinta ação de estudo é o controle, que permite ao estudante determinar se as quatro ações anteriores foram realizadas conforme previam as condições e as exigências da tarefa de estudo, possibilitando, com isso, o cumprimento efetivo daquelas ações de acordo com a sua composição operacional e com a forma correta de sua execução.

A sexta e última ação de estudo é a avaliação, que permite ao estudante a verificação do resultado da tarefa de estudo, determinando se o procedimento geral utilizado em sua resolução está ou não assimilado e se os objetivos das 
ações correspondem ou não a seu resultado final. Em síntese, nesse processo, torna-se possível o exame qualitativo e essencial dos resultados e dos procedimentos necessários para formação do conceito formado em relação à finalidade da tarefa de estudo.

Tendo em vista todas as questões apontadas, é fundamental, para pensarmos a organização das ações pedagógicas voltadas à aprendizagem das crianças, termos consciência das particularidades do pensamento teórico como neoformação decorrente da atividade de estudo e de todos os elementos que a constituem: as capacidades que, em suas relações dialéticas, formam a totalidade do pensamento teórico - análise, reflexão e planificação mental.

\section{As capacidades de análise, reflexão e planificação mental como as neoformações da atividade de estudo}

Iniciamos este tópico relativo às capacidades vinculadas ao pensamento teórico pelo conceito de análise, que, no processo de materialização da atividade de estudo, organiza a primeira ação da tarefa de estudo, que, como dissemos antes, é considerada a mais importante de todas as ações que a compõem (DAVIDOV, 1988). Podemos conceituar a capacidade de análise como a ação de procura, identificação e assimilação das relações genéticas e originais de um conjunto de objetos particulares, que encontra, a partir de um aspecto, característica ou qualidade, a relação essencial do problema. Seu papel, no processo de solução da tarefa de estudo, é, então, identificar os nexos essenciais ou princípios que estão implícitos na resolução objetiva de um problema, que é diretamente inseparável das condições, dos meios e dos fins característicos da tarefa de sua resolução.

No processo de condução da ação de análise, o sujeito produz as condições e os meios para a transformação das relações que estão presentes nos elementos do problema e, a partir desse processo, cria novos meios de se relacionar com as situações-problema e, como consequência, forma um conjunto funcional de modos de ação da análise que lhe permite generalizar os elementos do problema em situações diversas. 
A ação de análise tem relação dialética com o processo de síntese; no pensamento teórico, a análise e a síntese estão intimamente relacionadas: a análise sem a síntese é insuficiente, pois o uso unilateral da análise pode levar à redução da totalidade, tornando-a um processo de mecanização e mera soma das partes. Por sua vez, também não é possível no pensamento teórico o contrário, a síntese sem a ação de análise, porque a síntese no ato de pensar tem a função de estabelecer as relações essenciais dos elementos da totalidade. Nas palavras de Petrovski,

Análise é a identificação no objeto de aspectos, elementos, propriedades, conexões, relações etc., é a divisão do objeto do conhecimento em diversas partes e componentes. A unificação dos componentes do todo separado na análise é a síntese. No processo de síntese se produz a união, a correlação dos elementos em que tinha se divido o objeto de conhecimento. (PETROVSKI, 1980, p. 302, tradução nossa).

Em resumo, a análise decompõe o problema, e a síntese volta a reunir os elementos buscando a sua resolução, mas essa reunião acontece de forma qualitativamente diferente, porque, analisando e sistematizando, o pensamento passa de uma representação vaga do objeto para a formação do conceito - a ideia geral que analiticamente expressa os elementos essenciais que organizam dado objeto - e, sistematicamente, apresenta as relações essenciais do todo analisado. Análise e síntese convergem, então, como totalidade no processo de apropriação do conhecimento científico; em essência, permanecem inseparáveis e se desenvolvem em íntima relação dialética.

A análise teórica, no contexto da atividade de estudo, é a ação inicial que compõe a estrutura do método teórico de ação e possibilita a formação das capacidades do pensamento teórico-reflexivo para compreender a realidade; ao separar o que é essencial do todo, abre-se o caminho para a compreensão da totalidade em sua forma concreta, em movimento, cuja trajetória implica, no início dessa atividade, o processo de redução do concreto sensível ao abstrato e, na sequência, por meio de reflexões sucessivas, um processo de ascensão do abstrato ao concreto pensado "que expressa a natureza do pensamento teórico" (DAVIDOV, 1988, p. 148). 
A planificação mental é o segundo elemento que compõe a estrutura do método teórico de ação e possibilita a formação das capacidades do pensamento teórico-reflexivo. A planificação mental, no processo educativo, é um dos elementos que facilitam a aprendizagem das crianças, porque diz respeito à capacidade de elas anteciparem ações iminentes, definir modos diferentes de conseguir realizar uma tarefa, considerar as qualidades específicas de cada variante e optar pela melhor ação na resolução dos problemas.

Para compreender o movimento de desenvolvimento da capacidade de planificação mental, algumas de suas características devem ser definidas: o primeiro passo é entender que o ato de planejar tem origem na atividade. Os homens começam a planejar suas ações quando se deparam com um novo problema prático, para a solução do qual as ferramentas disponíveis são inadequadas, ou devem ser adaptadas ou readaptadas às novas condições.

O processo de adaptação se dá no nível e no campo da ideia, ou seja, no plano de uma ação iminente; seu resultado é uma programação de ações futuras. Isso faz da ação de planificação a base de orientação da atividade humana, definida e moldada nos objetos: ao planejar seus atos, os sujeitos recriam as imagens dos objetos e seu movimento no espaço e no tempo, criando mentalmente objetivos futuros a serem alcançados por suas ações. Além disso, em seu movimento, a ação de planificação cumpre a função de controlar a ordem em que qualquer encadeamento de operações deve ser realizado.

Como componente do método teórico de ação, a planificação mental deve ser tratada como uma função especial do pensamento reflexivo-teórico, pois ela é responsável por criar o movimento das relações e ações subjetivas, como também construir um sistema logicamente completo de ações ou operações, o que permite ao sujeito a construção de sistemas de ações potenciais, a esquematização ideal de um plano para futuras ações práticas, a construção e a reconstrução de diversas variantes dessas ações e a capacidade de optar corretamente entre elas, além da coordenação de tempo e de espaço por meio de um complexo encadeamento da análise das condições, objetivos e requisitos para solucionar a tarefa de estudo. 
A reflexão é o terceiro componente do método de ação que forma o pensamento reflexivo-teórico, capacidade essa que é fundamental para a criança em atividade de estudo, pois sem ela as ações de avaliação e controle que dela fazem parte não se concretizariam, uma vez que dependem da capacidade de refletir. Segundo Davídov,

O cumprimento de ações de controle e avaliação supõe que a atenção dos escolares esteja dirigida ao conteúdo das próprias ações, ao exame de seus fundamentos, do ponto de vista da correspondência com o resultado exigido pela tarefa. Semelhante exame, pelos escolares, dos fundamentos das próprias ações, chamado reflexão, conforma a condição essencial para que estas ações se estruturem e mudem corretamente. A atividade de estudo e alguns de seus componentes (em particular, o controle e a avaliação) se realizam graças a uma qualidade tão fundamental da consciência humana como é a reflexão. (DAVÍDOV, 1988, p. 184, tradução nossa).

Reorientar os sujeitos em relação ao seu próprio método de ação é, então, uma das principais funções da reflexão. O conteúdo e o sentido dessa reorientação são estabelecidos nos limites de quatro condições. A primeira, é a avaliação crítica dos motivos das transformações das condições objetivas como causas da mudança de suas próprias ações, bem como a revisão ou confirmação de suas visões de mundo, ou posições subjetivas. A segunda, refere-se às adaptações ou alterações nos planos e finalidades planejados de acordo com as transformações nas condições de ação. A terceira, é a avaliação crítica das ações para verificar se elas ainda respondem a todas as questões objetivas de um problema - seus resultados imediatos e consequências futuras -, acompanhando cada movimento do desenvolvimento e do desencadeamento lógico das ações. E, por fim, a quarta condição que corresponde ao exame crítico do conteúdo integral de seu método de ação como um método para resolução de um conjunto particular de problemas (MATVEEVA; REPKIN; SKOTARENKO, 2019).

Fechando essa discussão acerca das capacidades desenvolvidas pela atividade de estudo, ressaltamos o fundamental papel dessa atividade no processo de formação do pensamento teórico da criança, que se efetiva por meio da apropriação dos conhecimentos científicos, conteúdo da atividade, em íntima relação com o desenvolvimento das capacidades de análise, reflexão e planificação 
mental que se constituem como as principais neoformações do psiquismo infantil a partir dos anos iniciais do ensino fundamental da escola básica.

Após essa discussão, que apresentou conceitualmente as capacidades que constituem o pensamento teórico como neoformação das crianças em idade escolar, passaremos, agora, à explicitação do processo de desenvolvimento dessas capacidades dentro da atividade de estudo, evidenciando o movimento histórico desse processo, objetivando a formação de neoformações psíquicas como parte da formação da consciência teórica.

A compreensão desse processo requer a análise das condições de domínio das formas autônomas da atividade de estudo pelos estudantes, pois tais condições permitem revelar tanto a história do desenvolvimento das neoformações psíquicas de análise, reflexão e planificação mental como elementos do pensamento teórico, quanto o fato de essas capacidades estarem presentes desde do início da vida escolar como forma de ações de estudo.

O desenvolvimento dessas neoformações psíquicas acompanha a própria formação da atividade de estudo na criança, cujo processo supõe o trânsito da atividade realizada sob orientação do professor, no início da idade escolar, para a atividade de estudo efetivamente autônoma adquirida no processo de escolarização formal ao longo do ensino fundamental.

Matveeva, Repkin e Skotarenko (2019) apontam as características fundamentais do processo de realização da atividade de estudo para que ocorra essa transição. Partindo do ponto de vista de que essa atividade concretiza-se por meio da solução da tarefa de estudo, os autores evidenciam os seguintes elos que são fundamentais nesse processo: (1) a proposição da tarefa de estudo; (2) a aplicação de ideias para sua solução; (3) a realização do controle do andamento da tarefa e a avaliação objetiva de seus resultados.

A proposição da tarefa implica a definição, pelo próprio estudante, de uma meta a ser atingida, supondo, para isso, a sua percepção acerca do conteúdo a ser apropriado para a realização da tarefa. Implica, também, uma reflexão sobre os resultados que pretende conseguir, e, por isso, a meta, "como toda reflexão, é um produto da motivação do próprio sujeito". (MATVEEVA; 
REPKIN; SKOTARENKO, 2019, p. 332). A meta, como parte da estrutura da atividade de estudo a ser realizada, surge no processo de concretização dos motivos que levam a criança à solução da tarefa de estudo e possibilita a constituição do sentido que tem para ela essa tarefa.

Os motivos de aprendizagem e o consequente interesse pelos conhecimentos a serem apropriados são fundamentais tanto para o acolhimento da tarefa de estudo proposta pelo professor, quanto para a forma autônoma da atividade de estudo. Entretanto, esses motivos são qualitativamente diferentes para ambos os casos. A diferença está em que, se para o acolhimento, pelo estudante, da tarefa proposta pelo professor "é suficiente o interesse cognitivo da situação, então para sua proposição autônoma é necessário um interesse estável, claramente expresso, por uma dada área de conhecimentos teóricos" (MATVEEVA; REPKIN; SKOTARENKO, 2019, p. 332).

Esses interesses estáveis são fundamentais para que atividade de estudo autônoma se concretize ao longo do Ensino Fundamental em nossa realidade escolar. Além disso, eles se constituem como uma das condições para que ocorra o processo de internalização das ações de análise, reflexão e planificação mental que são, como afirmamos antes, as neoformações psíquicas a serem desenvolvidas durante esse período da vida escolar de cada sujeito.

O segundo elo para o processo de transição da atividade de estudo dirigida pelo professor para sua forma autônoma é o domínio de formas eficazes de resolução da tarefa de estudo. O ponto nevrálgico desse elo está na efetiva apropriação dos conceitos teóricos pelo estudante, que depende do desenvolvimento de sua capacidade de análise - pela qual ocorre a separação da ideia geral inicial, que é fixada por meio dos signos, possibilitando a construção da abstração essencial do objeto estudado -, e, também, de sua capacidade de generalização essencial do objeto a ser conhecido - pela qual são descobertos os vínculos regulares e constantes da relação inicial e suas consequentes manifestações expressas no conceito.

O terceiro elo que permite a transição da atividade de estudo dirigida pelo professor para a forma autônoma de sua realização é o controle e a avaliação do processo de solução da tarefa e dos seus resultados. Para Clarindo (2015), as 
ações de controle e avaliação têm uma função essencial na atividade de estudo: são elas que tornam possível, ao estudante, a realização efetiva do processo de descoberta da essência de objetos e fenômenos e suas relações objetivas por meio dos conhecimentos científicos, suplantando, assim, mera reprodução mecânica dos conteúdos culturalmente construídos pela humanidade.

Por meio da ação de controle, o estudante consegue manter a necessária integralidade operacional de todas as ações envolvidas na resolução da tarefa de estudo, fazendo com que o processo executivo de tais ações ocorra adequadamente. Com isso, ele tem a possibilidade de transformar o conjunto funcional das ações, e consequentemente, chegar à descoberta das relações e das particularidades existentes entre as ações que compõem a tarefa de estudo e os objetivos a serem alcançados.

A avaliação que o estudante faz das ações realizadas durante o cumprimento da tarefa de estudo permite-lhe o exame e a determinação dos procedimentos que são mais adequados e eficientes para a sua solução, além de facultar-lhe analisar se os resultados obtidos durante a execução da tarefa de estudo são os almejados pelos objetivos finais traçados. Deste modo, o estudante consegue realizar o exame qualitativo e essencial dos objetivos alcançados no processo de assimilação dos procedimentos fundamentais à realização da tarefa de estudo, não apenas em seus conteúdos operacionais, mas também nos princípios de ação que orientam esses procedimentos.

No processo histórico que leva ao desenvolvimento da atividade de estudo autônoma, as ações de avaliação e controle da aprendizagem precisam ser organizadas ao longo da vida escolar, para que, paulatinamente, deixem de ser uma incumbência do professor e passem a ser ações próprias do estudante que, nesse percurso de realização da atividade, desenvolve sua capacidade de controlar e avaliar sua aprendizagem, o que lhe permite realizar essas ações, inicialmente, sob orientação do professor e, depois, por ele mesmo, até chegar ao momento de autocontrolar e autoavaliar suas ações na atividade de estudo.

A apresentação das condições que possibilitam o desenvolvimento da atividade de estudo autônoma demonstra que o desenvolvimento das neoformações psíquicas das crianças em idade escolar - as capacidades de análise, reflexão e 
planificação mental próprias do pensamento teórico - resulta da historicidade do processo de desenvolvimento cultural e psíquico de cada ser humano singular. $\mathrm{O}$ estudante, por meio da atividade de estudo, realiza um percurso que, dialeticamente opõe o externo ao interno, o social ao individual, o geral ao particular, o concreto sensível ao concreto pensado, pelo qual não apenas apropriase de conhecimentos teóricos, mas também, em sua ação mental sobre eles, desenvolve as capacidades relacionadas ao pensamento teórico, forma modos de ação e procedimentos de ação e, acima de tudo, transforma sua personalidade nesse percurso. São esses vínculos que permitem a constatação da relação dialética entre atividade de estudo e as neoformações psíquicas da idade de escolar.

\section{Considerações Finais}

A organização dos processos educativos sistematizados, estabelecidos em nossa sociedade contemporânea para os anos iniciais do Ensino Fundamental da escola básica, favoreceriam um trabalho de formação da criança como ser pensante, reflexivo e capaz de soluções criativas para seus próprios problemas e para os que se apresentam em seu meio social, se favorecessem o desenvolvimento das neoformações psíquicas vinculadas às capacidades do pensamento teórico. Essa organização seria possível pela adoção de uma proposta teórico-metodológica de organização e implementação das ações de estudo, próprias e inerentes à atividade de estudo, reconhecida como atividade principal das crianças em idade escolar.

A atividade de estudo, portanto, como atividade principal das crianças em idade escolar, deve se estruturar de maneira que elas possam dirigir suas ações na direção da apropriação dos modos de ação - formas pelas quais agem, para que possam resolver a tarefa de estudo - e dos princípios generalizados de ação - leis e fundamentos gerais que regem o processo de formação de conceitos, utilizados para a solução da tarefa de estudo. Essas aquisições e, principalmente, o seu uso como instrumentos para alcançar os objetivos e metas próprios das tarefas de estudo que precisam resolver possibilitam às crianças o desenvolvimento de seu pensamento teórico e das capacidades a ele 
vinculadas: análise, reflexão e planificação mental, as neoformações psíquicas que se efetivam no processo de formação da atividade de estudo.

A relação entre atividade de estudo e o desenvolvimento das neoformações psíquicas das crianças em idade escolar está na forma de organização e, principalmente, na estrutura da atividade de estudo, que se caracteriza, como na atividade humana geral, por elementos de orientação motivo, fim e condição - e por elementos de operacionalização - atividade, ação, operação. A atividade de estudo, por seus elementos estruturais, dinamicamente postos em relação durante o processo de sua formação nos escolares dos anos iniciais do Ensino Fundamental, conduz à apropriação das capacidades do pensamento teórico.

Como decorrência desse processo, a criança em idade escolar internaliza modos e princípios de ação desenvolvidos durante a atividade de estudo, utilizando-os para a solução de novos problemas para cuja solução vale-se dos conhecimentos científicos apropriados no processo de aprendizagem, bem como lança mão das capacidades de análise, reflexão e planificação mental, que são desenvolvidas no decorrer do processo de formação da atividade de estudo e que se tornam parte das capacidades gerais do sujeito e constituintes do seu psiquismo e personalidade.

\section{Referências}

CLARINDO, C. B. S. Atividade de estudo como fundamento do desenvolvimento do pensamento teórico de crianças em idade escolar inicial. Dissertação (Mestrado em educação), Faculdade de Filosofia e Ciências, Universidade Estadual Paulista "Júlio de Mesquita Filho", Marília, 2015.

DAVÍDOV, V. La enseñanza escolar y el desarrollo psíquico: investigación psicológica teórica y experimental. Editorial Progeso: Moscou, 1988.

DAVYDOV, V. V. What is real learning activity? In: HEDEGAARD, M. and LOMPSCHER, J. Learning activity and development. Aarhus: Aarhus University Press, 1999, p. 123-138.

LEONTIEV. A. N. Actividad, conciencia y personalidad. Buenos Aires: Ediciones Ciencias Del Hombre, 1978. 
LEONTIEV, A. N. Uma contribuição à teoria do desenvolvimento da psique infantil. In: VIGOTSKII, L. S.; LURIA, A. R.; LEONTIEV, A. N. Linguagem, desenvolvimento e aprendizagem. 5. ed. São Paulo: Ícone, 1988, p. 59-83.

LEONTIEV. A. N. O desenvolvimento do psiquismo. 2. ed. São Paulo: Centauro, 2004.

LOMPSCHER, J. Learning activity and its formation: ascending from the abstract to the concrete. In: HEDEGAARD, M. and LOMPSCHER, J. Learning activity and development. Aarhus: Aarhus University Press, 1999, p. 139-166.

MATVEEVA. N.I, REPKIN, V. V. SKOTARENKO.R.V. Condições de domínio das formas Autônomas da atividade de Estudo. In: PUENTES, R. V, CARDOSO, G. C. G., AMORIM, P. A. P. Teoria da atividade de estudo: contribuições de D. B. Elkonin, V. V. Davidov e V. V. Repkin - Livro I . Editora CRV/EDUFU/ Curitiba/Uberlândia, 2019. DOI: https://doi.org/10.24824/978854443380.5.

PETROVSKY, A.V. Psicología General. Moscú: Editorial Progreso, 1980.

REPKIN, V. V. Ensino desenvolvente e atividade de estudo. Ensino Em Re-vista, v. 21 , n. 1, p. 85-99, jan./jul. 2014.

RUBInSTEIN, S. L. Principios de Psicología General. México: Editorial Grijalbo, 1974.

VIGOTSKII, Lev Semenovich. Aprendizagem e desenvolvimento intelectual na idade escolar. Linguagem, desenvolvimento e aprendizagem. 5. ed. São Paulo: Ícone, 1988, p. 103-117.

VYGOTSKI, L. S. Obras Escogidas. Tomo II. Madrid: Machado Nuevo Aprendizaje, 2001.

VYGOTSKI, L. S. Obras Escogidas. Tomo III. Madrid: Machado Nuevo Aprendizaje, 2012. 